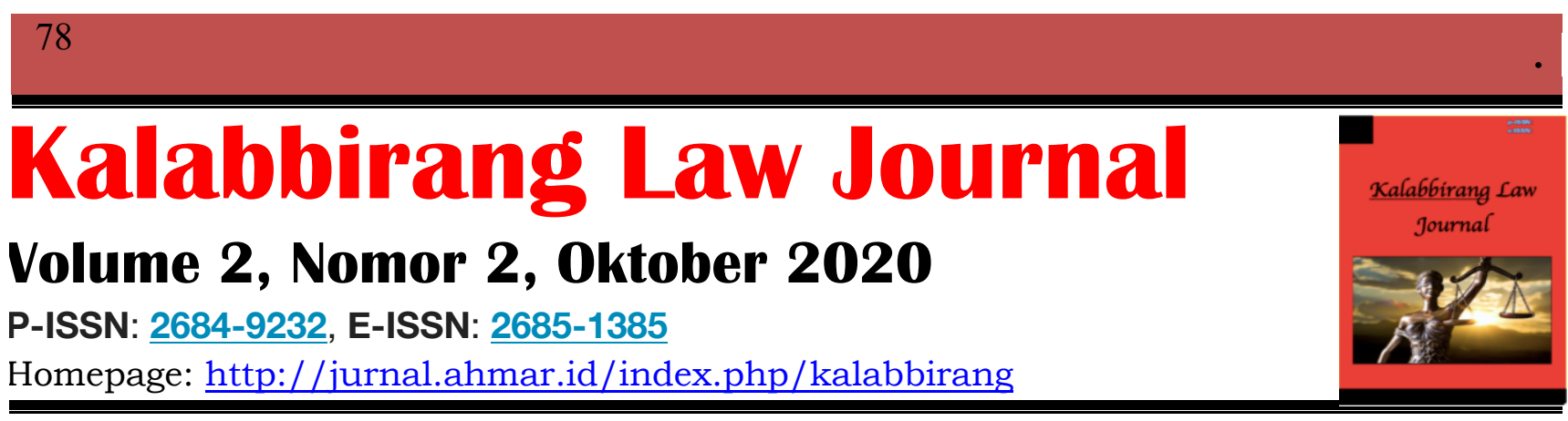

\title{
Kebijakan Hukum Lingkungan Terhadap Penanggulangan Krisis Iklim Di Indonesia
}

\author{
Wahyudin ${ }^{1}$ Said Sampara ${ }^{2}$ \& Hamza Baharuddin ${ }^{3}$ \\ ${ }^{1}$ Magister Ilmu Hukum, Universitas Muslim Indonesia, Indonesia \\ ${ }^{2,3}$ Fakultas Hukum, Universitas Muslim Indonesia \\ Koresponden, Email: wahyudin.wahyudin@gmail.com
}

\begin{abstract}
ABSTRAK
Kebijakan Hukum Lingkungan Terhadap Penanggulangan Krisis Iklim di Indonesia sampai saat ini telah dilakukan oleh Pemerintah Indonesia secara bertahap. Hal ini dibuktikan dengan keikutsertaan Pemerintah didalam Konvensi Perubahan Iklim, protocol Kyoto, Paris Agremeent, dan Bali Roadmap. berkomitmen bersama Negara-negara anggota PBB menandatangani Komitmen didalam forum Internasional untuk ikut menanggulangi pemanasan global. Komitmen tersebut dituangkan dalam Undang-Undang, Peraturan Pemerintah dan pengejawantahan komitmen tersebut di tuangkan dalam Peraturan Presiden Nomor 61 Tahun 2011 tentang Rencana Aksi Nasional Penurunan Emisi Gas Rumah Kaca. 2) Upaya Pengendalian Krisis Iklim di Indonesia dilakukan melalui adaptasi dan mitigasi, Upaya adaptasi, difokuskan pada area yang rentan terhadap perubahan iklim, yakni: sumber daya air, pertanian, perikanan, pesisir dan laut, infrastruktur dan pemukiman, kesehatan, dan kehutanan. Upaya mitigasi dengan cara menghemat penggunaan listrik dan air, Melakukan ${ }_{5} \mathrm{R}$ (Rethink, Reduce, Reuce, Recycle, Replace), Memanfaatkan energi alam semaksimal mungkin, Menggunakan peralatan ramah lingkungan, Melakukan kegiatan penghijauan, Efektivitas penggunaan kendaraan, Mengajak orang-orang sekitar Anda untuk melakukan hal yang sama
\end{abstract}

Kata Kunci: Kebijakan Hukum; Hukum Lingkungan; Krisis Iklim

\begin{abstract}
The Environmental Law Policy on Overcoming the Climate Crisis in Indonesia to date has been carried out by the Government of Indonesia in stages. This is evidenced by the Government's participation in the Climate Change Convention, the Kyoto protocol, the Paris Agremeent, and the Bali Roadmap. commit with the United Nations member states to sign a commitment in an international forum to help combat global warming. The commitment is outlined in the Law, Government Regulation and the manifestation of that commitment is contained in Presidential Regulation No. 61 of 2011 concerning the National Action Plan for Reducing Greenhouse Gas Emissions. 2) Efforts to Control the Climate Crisis in Indonesia are carried out through adaptation and mitigation. Adaptation efforts are focused on areas that are vulnerable to climate change, namely: water resources, agriculture, fisheries, coastal and marine, infrastructure and settlement, health and forestry. Mitigation efforts by saving electricity and water use, Performing 5R (Rethink, Reduce, Reuce, Recycle, Replace), Utilizing natural energy as much as possible, Using environmentally friendly equipment, Conducting greening activities, Effectiveness of vehicle use, Inviting people around you to do the same thing
\end{abstract}





\section{PENDAHULUAN}

Perintah Allah SWT kepada manusia agar melestarikan alam dan lingkungannya karena sudah diatur oleh Yang Maha kuasa. Penegasan Allah SWT bahwa berbagai kerusakan yang terjadi di darat dan di laut adalah akibat ulah atau perbuatan manusia, oleh karena itu hendaklah manusia menghentikannya dan mau kembali kejalan yang benar yaitu dengan menggantikannya dengan perbuatan yang baik. Allah SWT menyuruh agar manusia mempelajari umat-umat terdahulu (sejarah), banyaklah bencana yang menimpa kepada umat-umat terdahulu disebabkan mereka tidak menghiraukan seruan Allah, bahkan kebanyakan mereka ingkar dan musyrik kepada-Nya. Dalam Al Qur'an Surah Al Rum 41 - 42

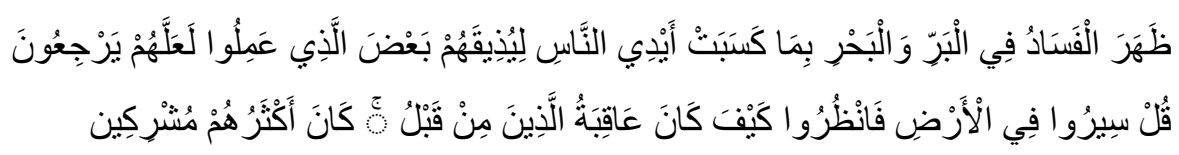

"Telah tampak kerusakan di darat dan di laut disebabkan karena perbuatan tangan manusia; Allah menghendaki agar mereka merasakan sebagian dari (akibat) perbuatan mereka, agar mereka kembali (kejalan yang benar). (41) Katakanlah (Muhammad), “ Bepergianlah di bumi lalu lihatlah bagaimana kesudahan orang-orang dahulu. Kebanyakan dari mereka adalah orang-orang yang mempersekutukan (Allah)."(42)

Qur'an Surat Al Ruum adalah surat yang ke 30 terdiri atas 6o ayat, termasuk golongan suratsurat Makiyyah. Dinamakan Ar Ruum karena pada permulaan surat ini yaitu ayat 2, 3, dan 4 terdapat pemberitaan bangsa Rumawi yang pada mulanya dikalahkan oleh bangsa Persia, tetapi setelah beberapa tahun kemudian kerajaan Ruum dapat menuntut balas dan mengalahkan kerajaan Persia kembali. Pada Q.S. Ar Rum ayat 41 - 42 menerangkan bahwa Allah SWT menciptakan alam semesta dan segala isinya adalah untuk dimanfaatkan oleh manusia demi kesejahteraan hidup dan kemakmurannya. Manusia diangkat sebagai khalifah di bumi yang di amanati agar menjaga kelestarian alam jangan sampai rusak. Manusia diperbolehkan menggali kekayaan alam, mengolahnya, dan memanfaatkan sebagai bekal beribadah kepada Allah dan beramal soleh. Namun kenyataannya karena manusia mempunyai sifat tamak, rakus, (yang berlebihan) sehingga penggalian alam itu tak terkendalikan yang berdampak menjadi bencana alam, seperti tanah longsor, banjir, alam menjadi tandus, kekeringan, alam menjadi gersang, dan udara tercemar dan lain sebagainya. Kerusakan alam itu akan berakibat pula kesengsaraan pada diri manusia itu sendiri. Oleh karena itu manusia disuruh mempelajari sejarah sebelumnya bahwa banyak manusia yang menjadi sengsara akibat mereka tidak mau lagi menghiraukan

Dari Serangkain revolusi yang telah terjadi dalam bidang politik, ekonomi,dan sosial di beberapa Negara tidak ada yang dapat memberikan perubahan besar-besaran terhadap nilai dan perilaku manusia dalam menjalankan kehidupan sebesar sumbangsih dari revolusi Lingkungan. Salah satu isu lingkungan hidup yang memberikan pengaruh signifikan terhadap semua komponen kehidupan dan sistem kehidupan di banyak kalangan saat ini adalah mengenai fenomena Perubahan Iklim (Climate Change) (Bram, 2011). PBB mengungkap 2019 menjadi tahun 'terpanas' dalam periode lima tahun terakhir. 
Laporan PBB tersebut menuliskan rata-rata suhu global pada 2015-2019 berada dalam jalur 'terpanas'. Dikutip dari AFP, iklim periode ini diperkirakan naik 1,1derajat Celcius di atas era pra-industri (1850-1900) dan o,2 derajat Celcius lebih hangat sejak 2011-2015. Empat tahun terakhir ini sudah menjadi terpanas sejak pencatatan iklim dan cuaca dimulai pada 1850. Mengutip dari Laman Resmi Bmkg Suhu tertinggi di Indonesia terjadi pada tanggal 24 September 2019, 37 derajat Celcius tepatnya di Kota Banjarmasin.

Greenpeace Indonesia menyebut, fenomena hujan ekstrem di wilayah jabodetabek bukan fenomena perubahan iklim tetapi sudah masuk kategori Krisis Iklim dan Bukti Krisis Iklim secara global bisa kita lihat dari salah satu kasus yaitu bencana Kebakaran Hutan Amazon di Brasil dan melehnya gletser Gunung Okjokull di Islandia, Citra satelit milik NASA menunjukkan lebih dari 9.50o kebakaran telah terdeksi dan menambah total 73.00o dari Januari- agustus 2019 yang membuat kita kehilangan 20\% oksigen Dunia (Agustiar, et.al, 2020). Indonesia juga terkena dampak krisis Iklim yaitu Kebakaran Hutan di Sumatera dan Kalimantan yang sangat berdampak pada Indonesia dan bagi dunia Internasional (Rasyid, 2014)

Pada tanggal 3 Oktober 2009 Pemerintah Republik Indonesia mengesahkan dan mengundangkan Undang-Undang Nomor 32 tahun 2009 tentang Perlindungan dan Pengelolaan Lingkungan Hidup, yaitu upaya sistematis dan terpadu yang dilakukan untuk melestarikan fungsi lingkungan hidup dan mencegah terjadinya pencemaran dan/atau kerusakan lingkungan hidup yang meliputi perencanaan, pemanfaatan, pengendalian, pemeliharaan, pengawasan dan penegakan hukum. Terdapat beberapa Pasal dari UndangUndang Nomor 32 tahun 2009 yang berhubungan dengan perubahan iklim, Pasal 57 ayat (1) huruf c dan ayat 4, yang menetapkan, pemeliharaan lingkungan hidup dilakukan upaya pelestarian fungsi atmosfer, meliputi: upaya mitigasi dan adaptasi perubahan iklim, upaya perlindungan ozon, dan upaya perlindungan terhadap hujan asam.

\section{METODE PENELITIAN}

Tipe penelitian yang penulis gunakan adalah penelitian hukum Normatif, yaitu dengan mengkaji ketentuan hukum lingkungan sebagai norma berupa prinsip-prinsip hukum,normanorma hukum, dan peraturan-peraturan hukum. Pendekatan penelitian yang digunakan adalah pendekatan perundang-undangan (statute approach) dan pendekatan konsptual (conseptual apprpach) (Peter Mahmud Marzuki, 2016:137-177). Data yang diperoleh baik data primer maupun data sekunder dikategorikan sesuai jenis datanya. Kemudian data tersebut dianalisis dengan menggunakan metode kualitatif, yaitu menganalisis data yang berhubungan dengan masalah yang diteliti, kemudian dipilih berdasarkan pikiran yang logis untuk menghindarkan kesalahan dalam proses analisis data. Hasil yang diperoleh dipaparkan secara deskriptif, yaitu dengan menguraikan, menjelaskan, dan menggambarkan sesuai dengan permasalahan dalam penelitian ini. 


\section{PEMBAHASAN}

\section{A. Kebijakan Hukum Lingkungan terhadap Penanggulangan Krisi Iklim Di Indonesia}

Kebijaksanaan Pemerintah Indonesia terhadap upaya penanggulangan Krisis iklim melakukan langkah-langkah baik dalam rangka mengimplementasikan voluntary commitment yang terdapat dalam Protokol Kyoto maupun dalam bentuk mandatory commitment sebagai hasi dari Copenhagen accord. Indonesia memproduksi gas rumah kaca dalam jumlah yang ralatif signifikan.Emisi Gas Rumah Kaca (GRK) Indonesia berkontribusi sebesar 5 persen dari total emisi GRK dunia.Kontribusi tersebut jauh lebih tinggi dibandingkan dengan kontribusi kepada Produk Domestik Bruto (PDB) dunia, sebesar o,6 persen. Indikator ini menunjukkan bahwa laju kenaikan emisi GRK jauh diatas kenaikan PDB,serta memberikan indikasi arah pertembuhan ekonomi Indonesia yang tidak berkelanjutan.

Berdasarkan data yang dikumpulkan Carbon Dioxide Information Analysis Center jika dilihat hanya dari emisi karbondioksida dari sektor energi,maka Indonesia merupakan emitter ke-15 dunia dengan total emisi sebesar 397 juta Ton CO2. Dalam Peraturan Presiden Nomor 61 Tahun 2011 tentang Rencana Aksi Nasional Penurunan Emisi Gas Rumah Kaca, ditentukan bahwa terdapat 5 sektor utama yang harus melakukan tindak lanjut dalam rangka Rencana Aksi Nasional Gas rumah Kaca yaitu bidang Pertanian, Kehutanan dan lahan gambut, energy dan transportasi,industry dan pengelolaan limbah.

Tindak lanjut ini pun tidak hanya berhenti pada bebijakan pada tingkat Nasional , namun juga sampai pada tingkat lokal dengan membuat kebijakan-kebijakan mitigasi dalam instrument Rencana aksi Daerah gas Rumah Kaca dibawah koordinasi Menteri dalam Negeri, Menteri Perencanaan Pembangunan Nasional/Kepala Bappenas serta Menteri Lingkungan Hidup.

\section{Sektor Kehutanan}

Sumbangan Emisi GRK dari bidang berbasi lahan adalah sekita 67\% dari total emisi Nasional. Persentasi tersebut merupakan yang terbesar jika dibvandingkan dengan bidang lain .Meski demikian, bidang berbasis lahan, termasuk pertanian dan kehutanan, juga memberikan sumbangan sebsar 15\% dari total Produk Domestik Bruto nasioanl. Selain itu bidang-bidang berbasis lahan ini juga membantu pemulihan ekonomi Indonesia Setelah Krisis pada Tahun 1997-1998 melalui Peningkatan substansial dalam ekspor dan meberikan kesempatan kerja.

Wilayah Indonesia pada awalnya tertutup hutan, tempat-tempat yang tidak dapat mendukung pohon hanyalah lereng-lereng Gunung yang sangat curam dan jalur-jalur pesisis yang sempit .Setidaknya sampai tahun 1990, Indonesia masih tertutup hutan yang lebat. Pada tahun 1950, Dinas kehutanan Indonesia Menerbitkan Peta Vegetasi Indonesia Dimana dalam 
peta ini disimpulkan bahwa hampir $84 \%$ atau sekitar 162 juta ha, luas daratan Indonesia pada masa itu tertup oleh hutan primer.

\section{Sektor Transportasi}

Bila ingin menghentikan laju dari degradasi lingkungan, maka perubahan juga harus dilakukan dalam pola kehidupan manusia, karena aktifitas manusia cenderung berdampak langsung kepada kerusakan alam. Teknologi ramah lingkungan diupayakan agar dapat membantu proses perubahan tersebut, karena manusia saat ini dapat dikatakan telah mengalami kecanduan terhadap teknologi, dan dengan adanya teknologi ramah lingkungan tersebut maka manusia dapat ikut "menyelamatkan" lingkungan sekaligus memenuhi kebutuhan mereka.

Di lain sisi, kepemilikan mobil yang semakin hari semakin bertambah menyebabkan berbagai dampak buruk bagi lingkungan dan alam. Antara lain emisi gas yang menyebabkan polusi, konsumsi bahan bakar minyak yang berlebih dan kemacetan. Masih banyak penduduk Indonesia yang membutuhkan mobil sebagai transportasi jarak jauh (Aminah, 2018).

Sumber utama polusi udara di kota-kota besar Indonesia merupakan dari kendaraan bermotor dan juga kendaraan pribadi. Semakin macet kondisi lalu lintas, semakin besar polusi udara yang ditimbulkan (Ismiyati, Marlina \& Saidah, 2017). Hal tersebut hanya akan menambah kerugian pada negara. Penggunaan bahan bakar fosil pada kendaraan bermotor (mobil dan motor) merupakan salah satu sumber terbesar emisi Gas Rumah Kaca. Penggunaan kendaraan bermotor secara tidak efisien, misalnya dengan menggunakan kendaraan pribadi di bawah kapasitas angkutnya, atau penggunaan kendaraan bermotor untuk jarak pendek, akan meningkatkan emisi GRK secara signifikan (Rahman, 2013).

Misalnya karena isu lingkungan mulai menjadi permasalahan global, pada akhirnya dalam menarik minat para konsumen, perusahaan membuat kendaraan yang dikatakan sebagai kendaraan ramah lingkungan (Green car). Hal tersebut didukung dengan adanya kebijakan pemerintah yang dinamakan LCGC (Low Cost Green Car).

LCGC (Low Cost Green Car) sendiri merupakan salah satu kebijakan pemerintah di tahun 2013 yang sangat problematis. Kenapa dikatakan sebagai problematis? Kebijakan mobil murah ramah lingkungan besar kemungkinan akan berdampak negatif pada sektor transportasi darat dan energi (Denada \& Santora, 2013). Apalagi kebijakan ini diputuskan disaat masalah bahan bakar minyak (BBM) dan kemacetan lalu lintas belum tuntas diselesaikan. Kehadiran LCGC cenderung tidak menyelesaikan masalah tetapi justru menambah masalah demi masalah. Baik jangka pendek maupun jangka panjang. Pemerintah terlihat hanya mempertimbangkan aspek ekonomi secara parsial.

\section{Sektor Energi}

Menteri Energi dan Sumber Daya Mineral (ESDM) Ignasius Jonan mengatakan, sektor energi berkontribusi dalam perubahan iklim global. Dia pun mengimplementasikan berbagai kebijakan srategis, terutama di subsektor Energi Baru Terbarukan (EBT).Jonan menyebut, 
sektor kelistrikan menjadi salah satu penyumbang terbesar Perubahan iklim. "Salah satu penyebab global warming yang paling besar itu diakibatkan oleh (sektor) energi, terutama kelistrikan," kata Jonan, dikutip dari situs resmi Kementerian ESDM, di Jakarta, Selasa (17/9/2019). Kita bisa mengaliri listrik planet Bumi dua kali lipat dengan energi dari pembakaran bahan bakar fosil sehari-hari.Pembangkit listrik tenaga gas paling modern pun masih menyia-nyiakan 40\% gas dari bahan baku yang mereka bakar.

Desain sistem transportasi, gedung-gedung, dan alat-alat elektronik konvensional yang buruk juga menghamburkan banyak energi.Namun, sangat mungkin untuk memangkas energi yang terbuang secara drastis, sekaligus konsumsi energi global, dalam beberapa dekade.Sekitar 70\% dari konsumsi energi global masih belum memiliki standar efisiensi, sementara ada peluang untuk pengaturan efisiensi energi secara lebih efektif.

\section{B. Kebijakan Hukum Lingkungan Terhadap Pengendalian Krisis iklim Di Indonesia}

Kebijaksanaan Pemerintah Indonesia terhadap upaya penanggulangan Krisis iklim khususnya dalam upaya adaptasi dan mitigasi yang menjadi titik aksi yang konkrit guna menstabilkan iklim, agar semua permasalahan ini tidak terulang kembali. Adaptasi berarti menyesuaikan diri dengan dampak perubahan iklim, sedangkan mitigasi mengacu pada upaya mengurangi emisi gas rumah kaca melalui gaya hidup rendah emisi dalam kehidupan kita sehari-hari.

Setiap pemangku kepentingan, termasuk masyarakat, harus melakukan mitigasi dan adaptasi terhadap perubahan iklim. Menurut Wakil Menteri Lingkungan Hidup dan Kehutanan (LHK) sekaligus Ketua Tim Delegasi RI pada $\mathrm{COP}_{25}$ Madrid, Alue Dohong, adaptasi dan mitigasi merupakan kunci untuk mengatasi perubahan iklim.

1. Adaptasi Krisi Iklim Indonesia

Istilah 'adaptasi' dalam UNFCCC diartikan sebagai upaya penyesuaian diri kedalam sistem iklim yang berubah. Karena itu upaya pengurangan dampak/ resiko perubahan iklim, termasuk penanganan bencana, dalam konteks perubahan iklim/UNFCCC, termasuk ke dalam kategori adaptasi perubahan iklim. Karena kegiatan itu masuk kedalam pengertian menyesuaikan diri terhadap kondisi alam berubah yang diakibatkan oleh perubahan iklim.

Masalah perubahan iklim dalam konteks Kebijakan membutuhkan pergerakan secara tepat dan cepat terhadap risiko iklim saat ini secara efektif, dan pada saat bersamaan juga mampu mengembangkan sistem pembangunan yang tahan terhadap dampak perubahan iklim jangka-panjang (Iklim, 2012). Upaya tersebut membutuhkan pendekatan lintas-sektor baik pada tingkat nasional, regional, maupun lokal. Disamping itu, kita tidak boleh lupa bahwa upaya adaptasi harus disertai upaya mitigasi karena upaya adaptasi tidak akan dapat efektif apabila laju perubahan iklim melebihi kemampuan beradaptasi. Oleh karena itu dikhawatirkan bahwa pembangunan yang sedang dilaksanakan pemerintah bisa terhambat karena dampak perubahan iklim. Golongan yang paling rentan terhadap dampak perubahan iklim adalah masyarakat miskin yang juga merupakan golongan yang paling terkena dampak terhambatnya pembangunan nasional. Dengan demikian, respon terhadap perubahan iklim harus mengikutsertakan program pengentasan kemiskinan. Strategi nasional menghadapi 
perubahan iklim juga perlu diarahkan pada pengembangan rekayasa sosial agar masyarakat dapat mengalami perubahan sosial secara terencana, sistematis dan menyeluruh yang dapat memberikan manfaat bagi kelangsungan kehidupan sosial dan ekologi (Ichdayati, 2014)

Adaptasi terhadap perubahan iklim merupakan aspek kunci yang harus menjadi agenda pembangunan nasional dalam rangka mengembangkan pola pembangunan yang tahan terhadap dampak perubahan iklim dan gangguan anomali cuaca yang terjadi saat ini dan antisipasi dampaknya ke depan (Hilman, 2018). Tujuan jangka panjang dari agenda adaptasi perubahan iklim di Indonesia adalah terintegrasinya adaptasi perubahan iklim ke dalam perencanaan pembangunan nasional. Agenda adaptasi perubahan iklim harus difokuskan pada area yang rentan terhadap perubahan iklim, yakni: sumber daya air, pertanian, perikanan, pesisir dan laut, infrastruktur dan pemukiman, kesehatan, dan kehutanan. Untuk mencapai pembangungan yang tahan terhadap resiko iklim, pada masing-masing area fokus perlu untuk diketahui: 1) tujuan agenda perubahan iklim yang ingin dicapai terkait erat dengan tujuan pembangunan nasional, yang dapat juga diselaraskan dengan pencapaian Millenium Development Goals (MDGs) Indonesia; 2) kondisi yang ada pada masing-masing area fokus saat ini baik biofisik, program dan inisiatif yang ada serta institusi yang bertanggung jawab terhadap dampak perubahan iklim.

Diluar aspek substansi seperti yang diuraikan diatas, ada satu aspek penting dan strategis yang harus diperhatikan, yaitu aspkek hukum/perundangan. Sebenarnya, didalam Dokumen RAN-PI sudah disinggung aspek ini dengan istilah 'revitalisasi perundangan/peraturan yang ada. Untuk melakukan penyelarasan wilayah-wilayah kebijakan publik serta instrumen hukum dan perundang-undangan yang terkait, khususnya dalam sektor-sektor mitigasi dan adaptasi prioritas pembangunan termasuk sektor pengguna energi (seperti pembangkit listrik, industri, transportasi, serta domestik dan komersial), perdagangan, kehutanan, pertanian, perikanan/kelautan, pertambangan, dan infrastruktu

2. Mitigasi Krisi Iklim di Indonesia

Pengertian mitigasi adalah berbagai tindakan aktif untuk mencegah/ memperlambat terjadinya perubahan iklim/ pemanasan global \& mengurangi dampak perubahan iklim/pemanasan global (melalui upaya penurunan emisi GRK, peningkatan penyerapan GRK, dll.). Dalam praktek, pengertian mitigasi yang belakangan lebih banyak digunakan oleh para praktisi.

Menanggapi hal tersebut, sebagai pelaku utama terjadinya perubahan iklim bumi, maka manusia lah satu-satunya yang harus bertanggungjawab dalam upaya menanggulangi krisis iklim. Upaya mitigasi Konstruktif (membangun,membina,dan memperbaiki) terhadap krisis iklim yang dapat kita lakukan untuk menyelamatkan bumi antara lain:

a. Menghemat Penggunaan Listrik

Listrik merupakan salah satu sumber panas, yang berarti menyumbang pada peningkatan suhu bumi. Jika kita mencabut sumber listrik pada satu saja peralatan yang tidak terpakai, mungkin hasilnya tidak terasa. Tapi bagaimana jika 10 orang 
berpikir hal yang sama, dan semakin banyak aksi tersebut dilakukan, maka penghematan energi listrik menjadi sangat besar. Konsumsi daya pada pembangkit listrik pun berkurang, sehingga panas yang dihasilkan pun menurun

b. Menghemat Pemakaian air

Cuaca yang tidak dapat lagi diprediksi membuat bencana alam tak terduga bisa datang kapan saja, salah satunya adalah banjir. Volume air laut yang meningkat diakibatkan mencairnya es di kutub, membuat siklus turunnya hujan semakin sering. Apa hubungannya dengan menghemat air? Dengan tidak membuang-buang air, maka volume air di saluran buang yang tinggi tidak menjadi salah satu penyebab banjir, selain karena kebiasaan buang sampah sembarangan

c. Memanfaatkan Energi alam semaksimal Mungkin

Seperti memanfaatkan energi matahari pada siang hari untuk menerangi ruangan sehingga mengurangi pemakaian lampu dengan menggunakan kaca pada dinding. Jika ruangan menjadi panas karena itu, jendela bisa digunakan untuk memanfaatkan angin sebagai penyejuk udara, dibanding menggunakan pendingin udara. Penggunaan gorden pada jendela juga bisa mengurangi panas. Untuk skala yang lebih besar, bisa mulai membiasakan menggunakan energi baru terbarukan yang digalakkan oleh Kementrian Energi dan Sumber Daya.

d. Menggunakan Peralatan ramah lingkungan

Mengganti kantong plastik dengan tas kain sehingga bisa digunakan berulang adalah salah satu program yang kini tengah menjadi tren ramah lingkungan. Selain itu, menggunakan lap untuk mengurangi pemakaian tisu pun dapat mengurangi penebangan pohon untuk produksi tisu. Memanfaatkan teknologi dalam dunia kerja dan pendidikan, yakni dengan tidak banyak menggunakan kertas untuk tugas dan dokumen-dokumen yang tetap bisa dibahas secara digital. Jika terpaksa harus dicetak, bisa menggunakan sisi sebaliknya dari kertas yang telah tidak digunakan atau menggunakan bahan kertas ramah lingkungan

\section{KESIMPULAN}

Kebijakan Hukum Lingkungan Terhadap Penanggulangan Krisis Iklim di Indonesia sampai saat ini telah dilakukan oleh Pemerintah Indonesia secara bertahap. Hal ini dibuktikan dengan keikutsertaan Pemerintah didalam Konvensi Perubahan Iklim , protocol Kyoto, Paris Agremeent, dan Bali Roadmap. Bukan hanya itu, Pemerintah Indonesia juga berkomitmen bersama Negara-negara anggota PBB menandatangani di forum Internasional tersebut untuk ikut menanggulangi pemanasan global. Komitmen tersebut dituangkan dalam UndangUndang dan Peraturan Pemerintah antara lain : Undang-Undang Republik Indonesia Nomor 6 Tahun 1994 tentang Pengesahan Konvensi Perubahan Iklim,Undang-Undang Republik Indonesia Nomor 17 Tahun 2004 tentang Ratifikasi/Pengesahan Protokol Kyoto,Undang- 
Undang Republik Indonesia Nomor 27 Tahun 2007 tentang Pengelolaan Wilayah Pesisir dan Pulau-Pulau Kecil, dan Undang-Undang Republik Indonesia Nomor 24 Tahun 2007 tentang Penanggulangan Bencana. Pengejawantahan komitmen tersebut di tuangkan dalam Peraturan Presiden Nomor 61 Tahun 2011 tentang Rencana Aksi Nasional Penurunan Emisi Gas Rumah Kaca, pasal 2 ayat 2 menyebutkan bahwa "Kegiatan RAN-GRK meliputi : Pertanian, Kehutanan dan Lahan Gambut, Energi dan Transportasi, Pengelolaan limbah, Kegitan Pendukung lainnya" dan Upaya Pengendalian Krisis Iklim di Indonesia telah dilakukan melalui adaptasi dan mitigasi. Upaya adaptasi, seperti tertulis dalam Dokumen "Rencana Aksi Nasional dalam Menghadapi Perubahan Iklim" (lebih dikenal dengan Dokumen RAN-PI) telah difokuskan pada area yang rentan terhadap perubahan iklim, yakni: sumber daya air, pertanian, perikanan, pesisir dan laut, infrastruktur dan pemukiman, kesehatan, dan kehutanan. Upaya kedua yaitu mitigasi, yang dilakukan dengan cara menghemat penggunaan listrik dan air, Melakukan 5R (Rethink, Reduce, Reuce, Recycle, Replace), Memanfaatkan energi alam semaksimal mungkin, Menggunakan peralatan ramah lingkungan, Melakukan kegiatan penghijauan, Efektivitas penggunaan kendaraan, Mengajak orang-orang sekitar Anda untuk melakukan hal yang sama, dan sebagainya

\section{SARAN}

Adapun saran-saran penelitian ini adalah sebagai berikut:

1. Dalam konteks global perlu adanya penguatan negoisasi bagi Delegasi Republik Indonesia untuk Konferensi Perubahan Iklim, khususnya pada saat adanya pembahasan mengenai langkah-langkah nyata dalam perbaikan iklim. Keterpaduan antara kualitas dan kuantitas yang unggul dalam forum-forum Internasional akan membuat Indonesia lebih dapat memainkan peran serta menyuarakan kepentingan nasional guna menjamin hadirnya instrumen-instrumen internasional yang efektif dan berkeadilan.

2. Perlu adanya penguatan baik secara kelembagaan maupun secara regulasi yang mengedepankan isu Krisis Iklim dalam tataran yang lebih nyata. Hal ini dapat berupa hadirnya Peraturan Pemerintah yang terkait isu Krisis Iklim pada tingkat nasional. Kehadiran peraturan tersebut tudak hanya menegaskan komitmen Indonesia dalam perbaikan kondisi lingkungan, namun jiga dapat digunakan sebagai pedoman serta menegaskan kebijakan hukum pada tingkay pusat dan daerah dalam langkah mitigasi krisis iklim.

3. Ekosistem Mangrove memiliki keterkaitan erat dengan perubahan iklim maka perlu dihadirkan di setiap kota/kabupaten di Indonesia terutama untuk wilayah pesisir dalam bentuk suatu Kebijakan publik yang dituangkan dalam berbagai bentuk peraturan. Daniel Murdiyarso, Ilmuan utama Pusat penelitian kehutanan internasional (CIFOR) dalam forum internasional Blue Carbon Summit di Jakarta pada tanggal 18 Juli 2019 memaparkan penelitian terbarunya, bahwa Hutan mangrove Indonesia menyimpan lima kali lebih banyak karbon dibanding hutan daratan, Kehadiran Hutan Mangrove di seluruh penjuru Indonesia dari sabang sampai merauke tentu akan sangat bermanfaat dan 
kebanggaan untuk Dunia terlebih bangsa Indonesia

\section{DAFTAR PUSTAKA}

Agustiar, A. B., Mustajib, M., Amin, F., \& Hidayatullah, A. F. (2020). Kebakaran Hutan dan Lahan Perspektif Etika Lingkungan. Profetika: Jurnal Studi Islam, 20(2), 124-132.

Aminah, S. (2018). Transportasi Publik dan Aksesbilitas Masyarakat Perkotaan. Jurnal Teknik Sipil, 9(1), 1142-1155.

Bram, D. (2011). Perspektif Keadilan Iklim dalam Instrumen Hukum Lingkungan Internasional Tentang Perubahan Iklim. Jurnal Dinamika Hukum, 11(2), 285-295.

Denanda, M. W., \& Santosa, E. (2019). Analisis Pengaruh Kebijakan Low Cost Green Car Terhadap Perspektif Politik Lingkungan Dan Kesadaran Konsumen Dalam Mutu Ramah Lingkungan: Studi Kasus Lcgc Merek Dagang Toyota Di Semarang Selatan. Journal of Politic and Government Studies, 8(04), 371-380.

Hilman, D. (2018). Revitalisasi Peraturan Perundangan-Undangan Sebagai Upaya Strategis Penanganan Dampak Perubahan Iklim Di Indonesia. Jurnal Legislasi Indonesia, 6(1), 146-156.

Ichdayati, L. I. (2014). Respon Petani dan Adaptasinya terhadap Perubahan Iklim. Agribusiness Journal, 8(2), 155-170.

Iklim, D. N. P. (2012). Rencana Aksi Nasional Adaptasi Perubahan Iklim Indonesia. Kerjasama Bappenas, Kementrian Lingkungan Hidup, dan DNPI.

Ismiyati, I., Marlita, D., \& Saidah, D. (2014). Pencemaran udara akibat emisi gas buang kendaraan bermotor. Jurnal Manajemen Transportasi \& Logistik, 1(3), 241-248.

Rahman, M. A. (2013). Pembuatan mobil listrik untuk solusi transportasi ramah lingkungan (Mobil Baskara). Jurnal Riset Daerah, 12(2), 1819-1837.

Rasyid, F. (2014). Permasalahan dan dampak kebakaran hutan. Jurnal Lingkar Widyaiswara, 1(4), 47-59. 